\title{
Supporting Information \\ ESI-MS Insights into Acceptorless Dehydrogenative Coupling of Alcohols
}

Cristian Vicent ${ }^{* a}$ and Dmitry G. Gusev ${ }^{*, b}$

${ }^{a}$ Serveis Centrals d'Instrumentació Científica, Universitat Jaume I, 12071 Castellón, Spain

${ }^{b}$ Department of Chemistry and Biochemistry, Wilfrid Laurier University, Waterloo, Ontario N2L 3C5, Canada

\section{Corresponding Author}

*E-mail: barrera@uji.es

*E-mail: dgoussev@,wlu.ca

\section{Contents}

Figure S1. Experimental setup for the acquisition of the ESI mass spectra using the pressurized sample infusion (PSI) technique.

Figure S2. ESI mass spectra of catalyst 1 recorded via the PSI technique after heating 30 minutes (top) and 1 hour (bottom); peak assignments are depicted in Table S1.

Table S1. Summary of the species detected under catalytic conditions using catalyst $\mathbf{1 .}$

Figure S3. ESI mass spectra of ethanol $(2 \mathrm{~mL})$ in the presence of $0.05 \%$ of 3 (top) and 0.05 $\%$ of 3 and $1 \%$ EtONa after heating 30 minutes under reflux (bottom).

Table S2. Summary of the species detected under catalytic conditions using catalyst 3.

Figure S4. ESI mass spectra of ethanol $(2 \mathrm{~mL})$ in the presence of $0.05 \%$ of 4 after heating 2 hours under reflux.

Table S3. Summary of the species detected under catalytic conditions using catalyst 4. 


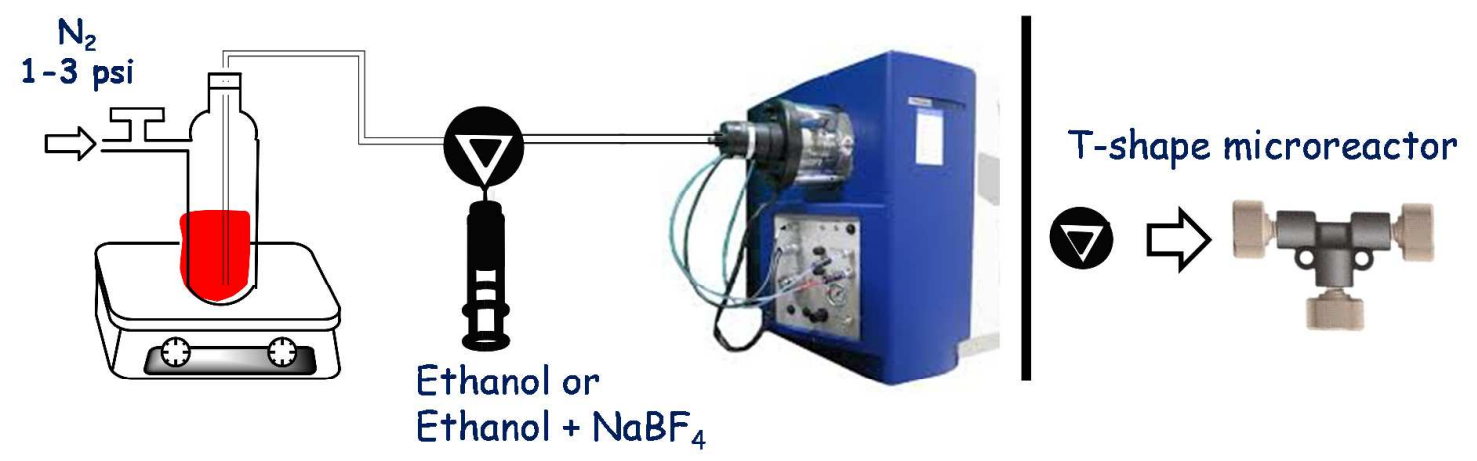

Figure S1. Experimental setup for the acquisition of the ESI mass spectra using the pressurized sample infusion (PSI) technique. Sample solutions were transferred to the ESI mass spectrometer under $\mathrm{N}_{2}$ positive pressure (1-3 psi) and further diluted with ethanol or ethanol in the presence of traces of $\mathrm{NaBF}_{4}(1 \%)$.
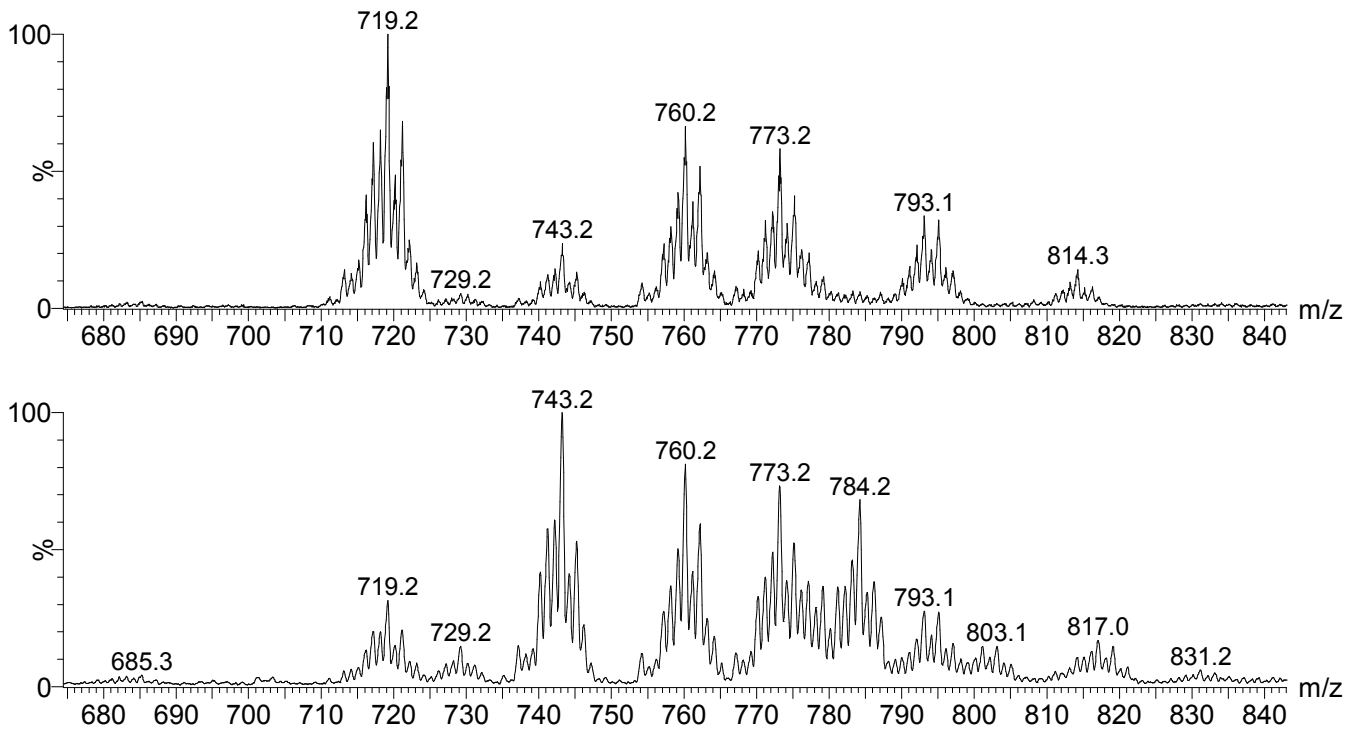

Figure S2. ESI mass spectra of catalyst 1 recorded via the PSI technique after heating 30 minutes (top) and 1 hour (bottom) under reflux; peak assignments are depicted in Table S1. 
Table S1. Summary of the species detected under catalytic conditions using catalyst $\mathbf{1 .}$

\begin{tabular}{|c|c|c|}
\hline intermediate & ESI detected species & $m / z$ value \\
\hline \multirow[t]{3}{*}{1} & {$[\mathbf{1}-\mathrm{Cl}]^{+}$} & $719.2^{\mathrm{c}}$ \\
\hline & {$[\mathbf{1}+\mathrm{Na}]^{+}$} & 777.2 \\
\hline & {$[\mathbf{1}+\mathrm{Na}+\mathrm{O}]^{+}$} & 793.1 \\
\hline \multirow[t]{2}{*}{$1 b$} & {$[1 \mathrm{~b}-\mathrm{H}]^{+}$} & 729.2 \\
\hline & {$[\mathbf{1 b}+\mathrm{Na}]^{+}$} & $753.2^{\mathrm{a}}$ \\
\hline \multirow[t]{2}{*}{$1 c$} & {$[\mathbf{1 c}-\mathrm{H}]^{+}$} & 773.2 \\
\hline & {$[\mathbf{1 b}+\mathrm{Na}]^{+}$} & $797.2^{\mathrm{b}}$ \\
\hline \multirow[t]{2}{*}{$1 e$} & {$[1 \mathrm{e}-\mathrm{H}]^{+}$} & $719.2^{\mathrm{c}}$ \\
\hline & {$[\mathbf{1 e}+\mathrm{Na}]^{+}$} & $743.2^{\mathrm{d}}$ \\
\hline \multirow[t]{2}{*}{$1 f$} & {$[\mathbf{1 f}-\mathrm{H}]^{+}$} & 773.2 \\
\hline & {$[\mathbf{1 f}+\mathrm{Na}]^{+}$} & 831.2 \\
\hline \multirow[t]{5}{*}{$1 g$} & {$[\mathbf{1 g}-\mathrm{Cl}]^{+}$} & $743.2^{\mathrm{d}}$ \\
\hline & {$[\mathbf{1 g}+\mathrm{OH}]^{+}$} & 760.2 \\
\hline & {$[\mathbf{1 g} \cdot \mathrm{O}+\mathrm{H}+\mathrm{Na}]^{+}$} & 784.2 \\
\hline & {$[\mathbf{1 g}+\mathrm{Na}]^{+}$} & 801.1 \\
\hline & {$[1 \mathrm{~g} \cdot \mathrm{O}+\mathrm{Na}]^{+}$} & 817.0 \\
\hline
\end{tabular}

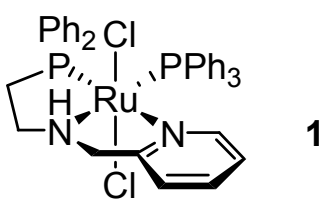

$\mathrm{Ph}_{2} \mathrm{OEt}$

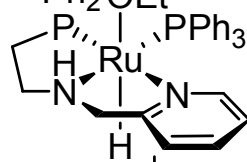

$1 b$
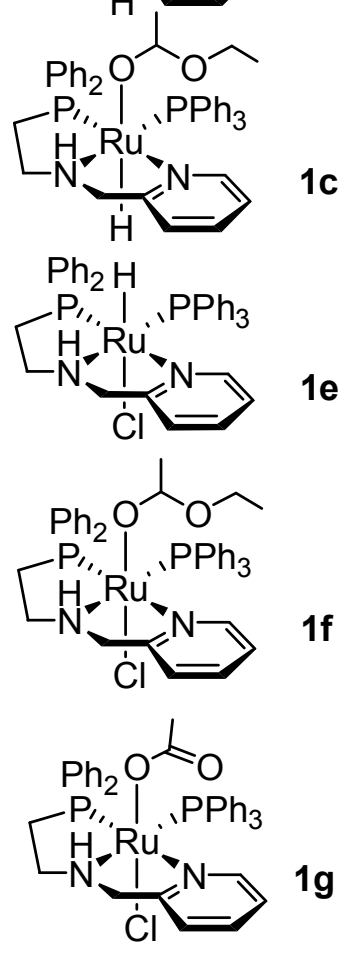

${ }^{\mathrm{a}}$ dilution with ethanol doped with $\mathrm{NaBF}_{4}$ was required to visualize the $\mathrm{Na}^{+}$ion adducts; ${ }^{\mathrm{b}}$ species $[\mathbf{1 b}+\mathrm{Na}]^{+}\left(\mathrm{m} / z\right.$ 797.3) was partially overlapped with $[\mathbf{1} \cdot \mathrm{O}+\mathrm{Na}]^{+}(\mathrm{m} / z \mathbf{z} 793.1){ }^{\mathrm{c}}$ the peak at $\mathrm{m} / \mathrm{z} 719.2$ was not diagnostic of the chemical composition of the identified $\mathbf{1}$ or $\mathbf{1 e}$ species. ${ }^{\mathrm{d}}$ species $[\mathbf{1 g}-\mathrm{Cl}]^{+}$and $[1 \mathbf{e}+\mathrm{Na}]^{+}$were unambiguously identified on the basis of CID experiments which revealed features due to the acetate $[1 \mathrm{~g}-\mathrm{Cl}]^{+}$species (losses of $\Delta \mathrm{m} 60$, $\left.\mathrm{CH}_{3} \mathrm{CO}_{2} \mathrm{H}\right)$ and chlorine $[1 \mathrm{e}+\mathrm{Na}]^{+}$species (losses of $\Delta \mathrm{m} 58, \mathrm{Na}^{35} \mathrm{Cl}$ ). 


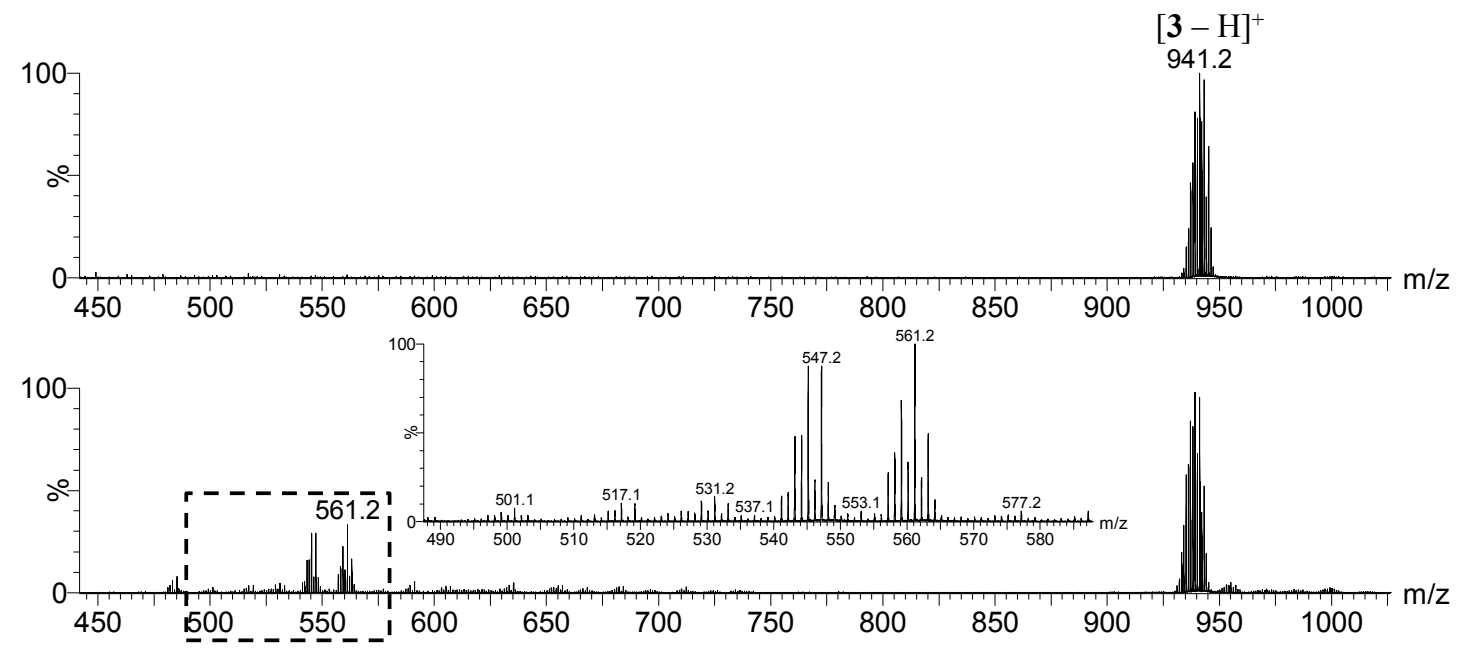

Figure S3. ESI mass spectra of ethanol $(2 \mathrm{~mL})$ in the presence of $0.05 \%$ of 3 (top) and $0.05 \%$ of 3 and $1 \%$ EtONa after heating 30 minutes under reflux (bottom).

Table S2. Summary of the species detected under catalytic conditions using catalyst $\mathbf{3}$.

\begin{tabular}{ccc}
\hline intermediate & ESI detected species & $\boldsymbol{m} / \boldsymbol{z}$ value \\
\hline 3 & {$[\mathbf{3}-\mathrm{H}]^{+}$} & 941.2 \\
& & \\
\hline $3 \boldsymbol{b}$ & {$[\mathbf{3 b}-\mathrm{H}]^{+}$} & 517.1 \\
& & \\
& {$[\mathbf{3 c}-\mathrm{H}]^{+}$} & 561.2 \\
\hline $\mathbf{c}$ & {$[\mathbf{3 c} \cdot \mathrm{O}-\mathrm{H}]^{+}$} & 577.2 \\
& \\
& {$[\mathbf{1 g}-\mathrm{H}]^{+}$} & 531.2 \\
& {$[\mathbf{1 g} \cdot \mathrm{O}-\mathrm{H}]^{+}$} & 547.2 \\
\hline $3 \boldsymbol{g}$ & \\
\end{tabular}

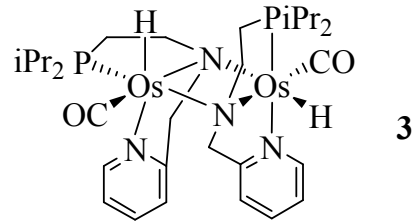

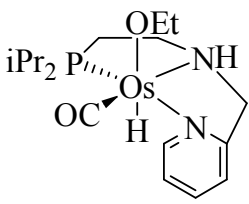

3b

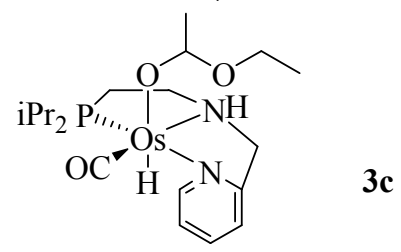

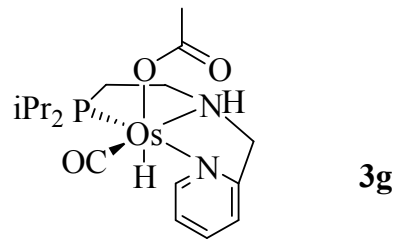

A minor peak at $\mathrm{m} / \mathrm{z} 473.1$ was observed; however, it was not diagnostic of the chemical composition of the identified species because it may correspond to $[\mathbf{3 b}-\mathrm{OEt}]^{+},\left[\mathbf{3 g}-\mathrm{CH}_{3} \mathrm{CO}_{2}\right]^{+}$or $[\mathbf{3 c}$ $\left.-\mathrm{C}_{4} \mathrm{O}_{2} \mathrm{H}_{9}\right]^{+}$. 


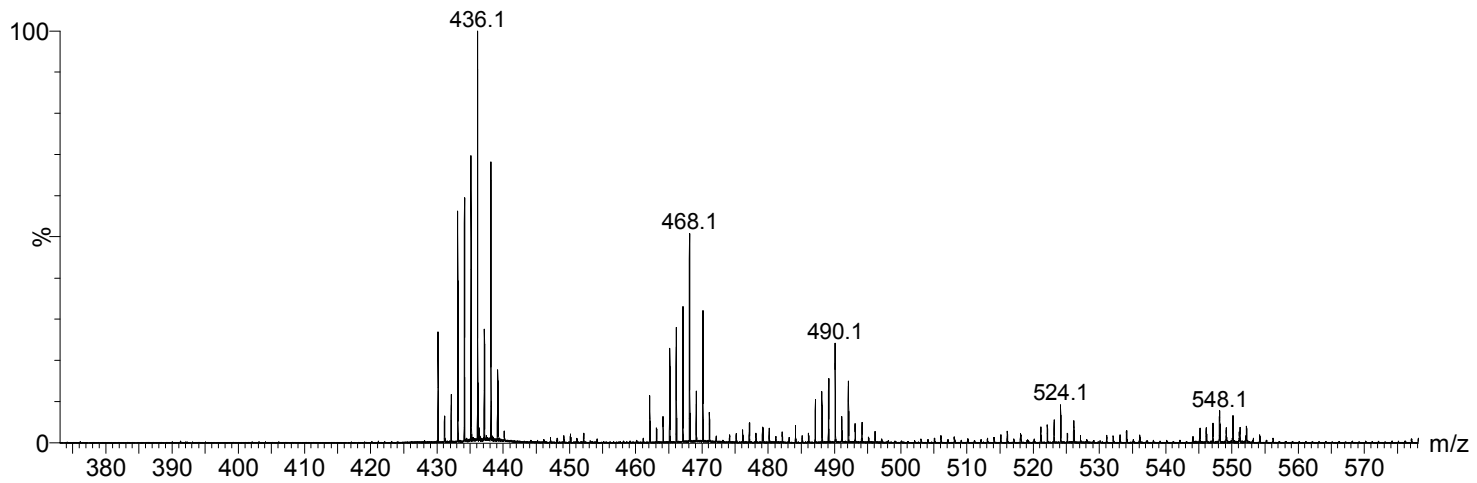

Figure S4. ESI mass spectra of ethanol $(2 \mathrm{~mL})$ in the presence of $0.05 \%$ of 4 after heating 2 hours under reflux.

Table S3. Summary of the species detected under catalytic conditions using catalyst 4.

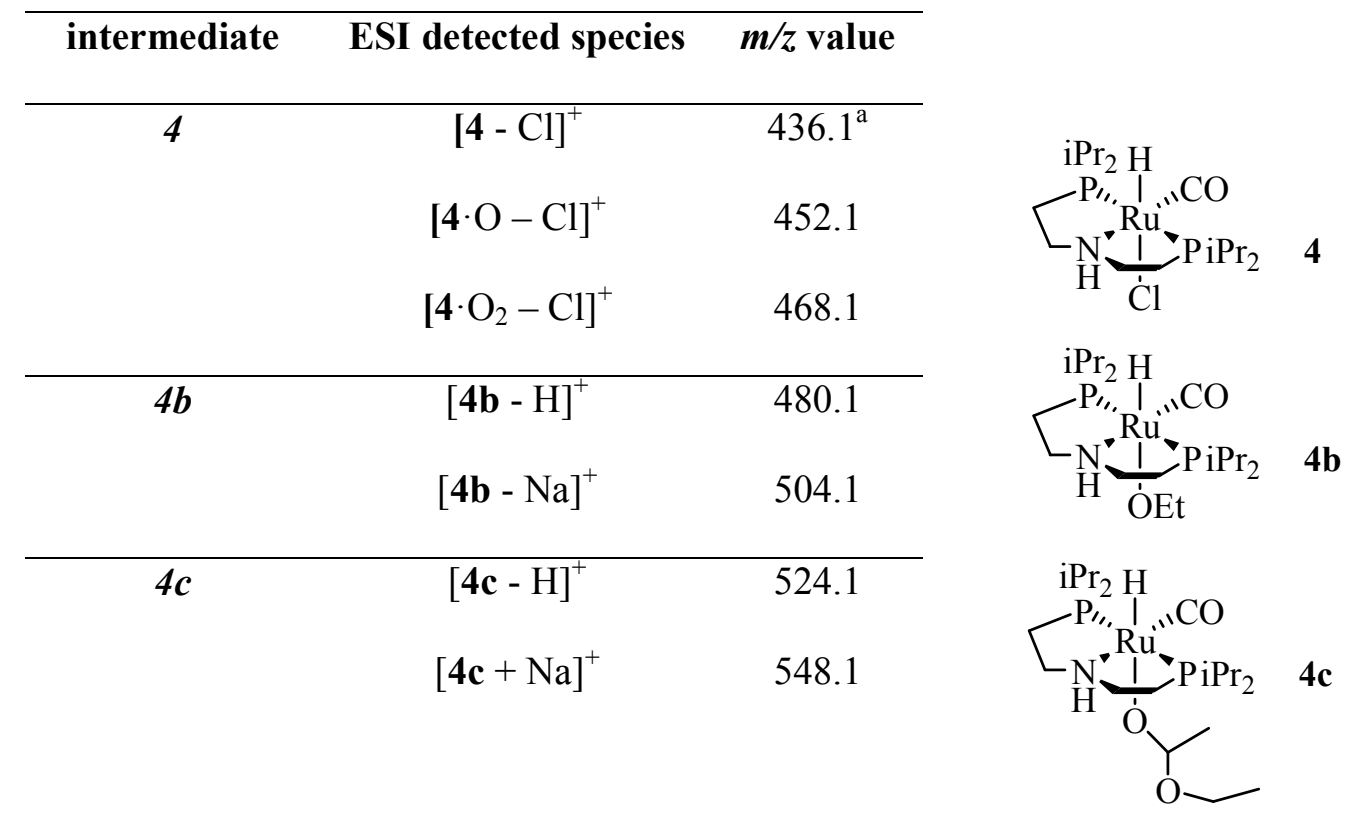

${ }^{a}$ species at $\mathrm{m} / \mathrm{z} 436.1$ was not diagnostic of the chemical composition of the identified species because it may also correspond to $[4 \mathbf{b}-\mathrm{OEt}]^{+}$or $\left[\mathbf{4} \mathbf{c}-\mathrm{C}_{4} \mathrm{O}_{2} \mathrm{H}_{9}\right]^{+}$ 